\title{
Significance of Micro Vessel Density in Invasive Breast Carcinoma
}

\author{
Divya Rani M.N ${ }^{1 *}$, Harendra Kumar M.L ${ }^{2}$ and Swaroop Raj B.V ${ }^{2}$ \\ 'Department of pathology, Bangalore Medical College, KR Market, Karnataka, India \\ ${ }^{2}$ Department of pathology, Sri Devraj Urs medical College, Tamaka, Kolar, Karnataka, India
}

\section{ABSTRACT}

Introduction: Breast cancer remains a leading cause of death in women of reproductive age group. Angiogenesis in breast carcinoma has been extensively studied and proven to play an important role is tumour outcome and patient prognosis. The prognostic relevance of angiogenesis expressed as microvessel density has been reported in various neoplasms.

Aim: Our aim was to study the correlation of microvessel density in breast carcinomas.

Methods: Microvessel density quantification was done using immunohistochemistry technique with CD34 monoclonal antibody in a series of 55 cases of breast carcinoma. Microvessels were counted within a $200 \mathrm{X}$ magnification field in the area of highest microvessel density and the results were correlated with tumour grade.

Result: Microvessel density was highest in grade III breast tumours (132 \pm 18.7$)$.

Conclusion: In the present study, intra tumoral mean MVD was highest in grade III tumors suggesting that tumour angiogenesis correlates with tumour grade. However larger sample size would be required to decide cut-off values between different grades.

Keywords: Breast Cancer, Micro Vessel Density, CD 34, Immunohistochemistry.

\section{Introduction}

Breast cancer is the most common occurring neoplasm seen in women worldwide, causing death in women between 35 and 55 years of age. Despite various screening modalities, diagnosis and treatment employed most of the women die from disease each year. ${ }^{[1]}$ In India breast cancer is one among the top three cancers. The incidence of breast cancer in Kolar District is around $6.41 \%$. ${ }^{[2]}$ There are many established prognostic indicators which can predict the tumour behaviour and survival in a patient with breast cancer like tumour size, histological grade, tumour type and axillary lymph node status. Hence these prognostic factors should be identified for benefit from adjuvant chemotherapy, as they can predict survival. One potential indicator in breast cancer is tumour-induced angiogenesis. Angiogenesis is the complex process that involves growth and formation of new blood vessels, which is a prerequisite for tumour growth and metastasis. In recent years, there has been evidence suggesting the quantification of intratumoral micro vessel density (MVD) by immunostaining for endothelial cell markers such as $\mathrm{CD}$ 31, CD34 \&VWF. A prognostic influence of micro vessel density has been demonstrated in variety of cancers, such as breast carcinoma, testicular tumours, gastric carcinoma, colorectal carcinoma, and even hematologic malignancies.
Angiogenesis is measured by quantifying micro vessel density (MVD) in sections taken and immuno stained for vascular endothelial cell markers. ${ }^{[3-8]}$

In present study, anti CD34 antibody was used to study microvessel density and correlated with grade of breast carcinoma.

\section{Materials and Methods}

Our study was a retrospective analysis of 55 cases of invasive breast carcinomas received in our department. For all cases, clinical details were noted. Surgical specimens were routinely processed after fixation with formalin and stained with $\mathrm{H} \& \mathrm{E}$ staining. All H\&E sections were examined and reviewed for histopathological type based on WHO classification of breast and graded based on Nottinghams Modified Scraff Bloom Richardson grading system.

Representative blocks were selected and sections were prepared for IHC. IHC was done using a primary antibody CD34 for determination of microvessel density.

Immunohistochemistry: Sections of $4 \mu \mathrm{m}$ thick were cut from blocks of resected primary tumors which were formalin fixed and paraffin embedded. Sections were stained for CD34 antigen using peroxidase-anti peroxidase method. Endothelial cells of tumour vessels 
were highlighted by this method. We used monoclonal antibody against CD 34 related antigen (Biogenex- CD34, QBEND/10 - undiluted). Diamino benzidine (DAB) was used as chromogen followed by $0.1 \%$ toluidine blue for counterstaining.

Quantification of Tumour Vascularity - Microvessel Density (MVD): Microvessel counts were preformed manually by light microscopy in areas of invasive tumour by two pathologists at a same time, in the areas of highest vascular density of the tumour.Any brown staining endothelial cell or endothelial cell cluster that are clearly separate from adjacent microvessels and other connective tissue element is considered as single countable microvessel. The presence of vessel lumen and RBCs was not required to classify a structure as a vessel. For MVD- intratumoral microvessels were defined as vessels without muscle layer within the main tumour mass surrounded by tumour cells. The slides from each tumour sections were scanned at $40 \mathrm{X}$ magnification using a light microscope (Olympus CX21i) to select areas with highest neovascularization (Hot spots).
Three such hot spots were selected and individual microvessel count was carried out at $200 \mathrm{X}$ field and then average of 3 hotspots was taken.

Statistical Analysis: Data was analysed using SPSS software version 6. Frequencies, mean and standard deviation (SD) were used to describe the data. Further ANOVA was used to describe the association between Microvessel densities with histological grade. A p- value < than 0.05 was considered as statistically significant.

\section{Results}

Our sample size included 55 cases with age ranging from 35 to $85 \mathrm{y}$, with mean age of $52 \pm 11.6$ years. Majority of the tumor presented with grade II on histology, comprising of $38(69 \%)$ cases. In the present study, the intratumoral mean MVD was highest in Grade III tumour (132 \pm 18.7$)$ and the value decreased as the tumour grade decreased. P value was $<0.05$ implying a strong significance between intratumoral mean MVD and histological grade. Mean MVD calculated was $78.6 \pm 29.8$. [Table-1][Figure- 1and 2]

Table 1: Association between intratumoral MVD \& grade of the tumour (ANOVA).

\begin{tabular}{|c|c|c|c|c|c|}
\hline Grade of the tumour & No. of subjects & Mean & Std. deviation & F value \\
\hline 1 & 11 & 51.18 & 23.194 & & \multirow{2}{*}{29.1} \\
\hline 2 & 38 & 78.21 & 20.485 & 0.002 \\
\hline Total & 6 & 132.00 & 18.772 & & \\
\hline
\end{tabular}

Table 2: Comparison of MVD with grade of tumor in different studies.

\begin{tabular}{|c|c|c|c|}
\hline Authors & $\begin{array}{c}\text { Grade 1 } \\
\text { Mean MVD } \pm \text { SD }\end{array}$ & $\begin{array}{c}\text { Grade 2 } \\
\text { Mean MVD } \pm \text { SD }\end{array}$ & $\begin{array}{c}\text { Grade 3 } \\
\text { Mean MVD } \pm S D\end{array}$ \\
\hline Kwon GY(2005) et al & $63.5 \pm 57.01$ & $101.09 \pm 41.64$ & $104.36 \pm 53.15$ \\
\hline Bolat (2006)et al & $14.7 \pm 3.2$ & $67.2 \pm 17.4$ & $85.3 \pm 21.3$ \\
\hline Safwat MD(2009) et al & $56.3 \pm 7.63$ & $88.9 \pm 7.53$ & $96.12 \pm 7.18$ \\
\hline Present study & $51.18 \pm 23.1$ & $78.21 \pm 20.4$ & $132 \pm 18.7$ \\
\hline
\end{tabular}

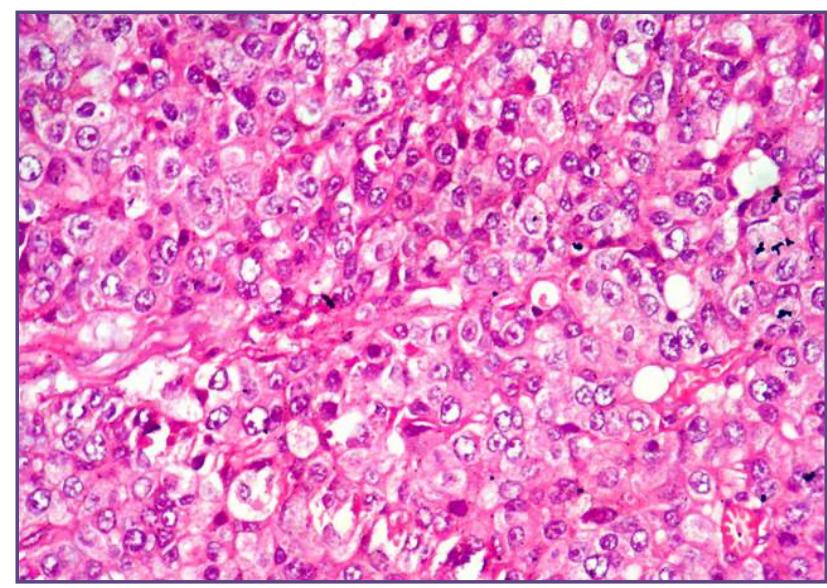

Fig. 1 : Histological grade 3, showing tumor cells arranged in sheets with marked nuclear pleomorphism and abundant mitotic activity (H\&E,400X).

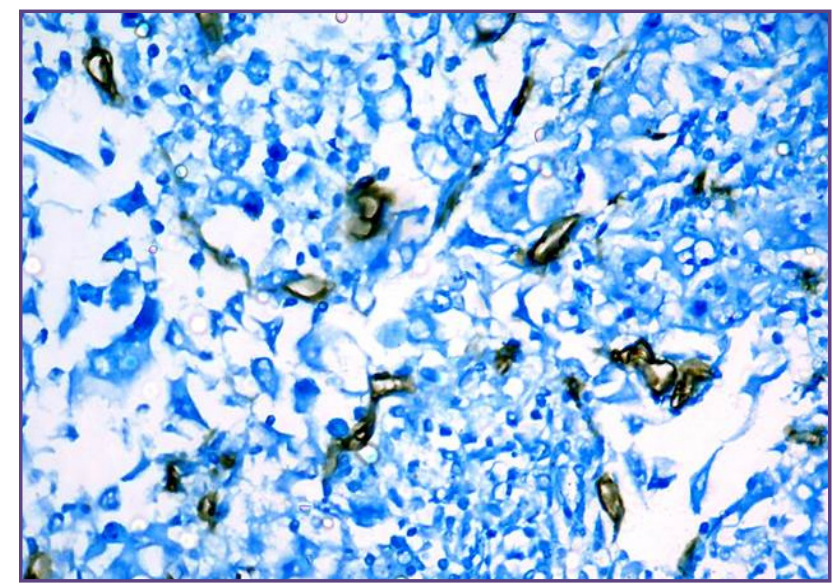

Fig. 2: CD 34 IHC showing microvessels grade 3 tumor (IHC,400X). 


\section{Discussion}

The role of the angiogenesis as an indicator of aggressiveness of the tumour has been demonstrated in several kinds of neoplasms such as a carcinoma breast, testicular tumours, melanoma and haematological malignancies. ${ }^{[5-7]}$ Tumour growth is dependent on angiogenesis. Expansion of the tumour requires nutrition which is provided by induction of new blood vessels. These newly formed blood vessels are leaky which allow tumour cells to enter circulation and thus increase the metastatic potential and probably the outcome for the patient. ${ }^{[3,9,10]}$ Popiela $\mathrm{TJ}$ et al, in his study showed that number of stained micro capillaries by CD34 seems to be a useful predictor for the development of local lymph node metastases in female invasive ductal breast cancer. ${ }^{[7]}$

Pyakurel D et al, in his study concluded that MVD positively correlated with size of the tumour, lymph nodes with tumour grade and aggressiveness. ${ }^{[1]}$

Teo et al showed that higher the microvessel densities in breast cancers, higher the risk of subsequent in situ cancer and invasive recurrence of previous in situ cancers with poorer response to treatment. ${ }^{[12]}$ Majority of published reports have shown a significant correlation between the density of intratumoral micro vessels in invasive breast carcinoma and the incidence of metastasis and or survival. ${ }^{[13]}$ Intratumoral microvessel density was found to be highest in grade III tumors in our study. Similar findings were noted in studies by Safwat et $\mathrm{al}^{[14]}(96.12 \pm 7.18)$, Bolat et $\mathrm{al}^{[15]}(85.3 \pm 21.3)$ and Kwon et $\mathrm{al}^{[16]}(104.36 \pm 53.15)$ showing mean MVD highest in Grade III tumors. All studies mentioned above showed mean MVD increasing as the grade increases. [Table 2]

Amin et al in his study showed lack of CD117 immunoreactivity was significantly related to the indicators of aggressiveness in breast cancer, such as the higher tumor grade, larger size, and more lymph node metastasis. ${ }^{[17]}$

The prognostic value of angiogenesis with different parameters is controversial. Many studies proved that MVD in invasive breast carcinoma has a prognostic value; however some authors did not. ${ }^{[7,11-18]}$ The reason for these discrepancies may be variations in the methodology used to identify microvessels, "Hot spots" counted, sample size, statistical analysis between the different studies.

\section{Conclusion}

In the present study, intratumoral MVD was highest in grade III tumors suggesting that intensity of tumour angiogenesis correlates with tumour grade. However larger sample size would be required to decide cut-off values between different grades.

\section{References}

1. Bernard U, Patrick N, Michael C, Gerard Y P. Micro vessel Density as a Prognostic factor in women with Breast Cancer: A Systematic Review of Literature \& Meta-analysis. Cancer Res 2004; 64: 2941-2955.

2. Kalyani R, Das S, Singh Bindra MS, Kumar HML. Cancer Profile in the Department of Pathology at Sri Devraj Urs Medical College ,Kolar : A ten years study. Indian Jr of Cancer $2010 ; 47$ : 160-5.

3. Li HJ, Jing J, Zhao YB, Zhu JQ, Zhang SY, Shi ZD. Tumor Angiogenesis in Node Negative Breast Carcinoma. A I Zheng 2002; 21: 75-8.

4. McCarthy N J, Yang X, Linniola I R, Merino MJ, Hewitt SM, Parr AL et, al. Microvessel Density, Expression of Estrogen Receptor ,MIB 1, p53 \& C erb 2 in Inflammatory Breast Cancer. Clin Cancer Res 2002; 8: 3857-62.

5. Da Silva BB, Lopes costa PV, dos Santos AR et al. Comparison of three Vascular Endothelial Markers in the Evaluation of Micro vessel Density in Breast Cancer. European Journal of Gynecological Oncology 2009; 30:285-8.

6. Murri AM, Hilmy M, Bell J et al. The relationship between the systemic inflammatory response, tumour proliferative activity, $\mathrm{T}$ lymphocytic and macrophage infiltration, microvessel density and survival in patients with primary operable breast cancer. British journal of cancer 2008; 99:1013-9.

7. Popiela TJ, Sikora J, Klimek M et al. The analysis of CD 34 antigen immunoreactivity in invasive ductal breast cancer with respect to the presence of lymph node metastasis. European journal of gynecological oncology2009;30:285-8

8. Kanjanapanjapol S, Wongwaisayawan S, Phuwapraisirisan S, Wilasrusmee C. Prognostic Significance of Microvessel density in Breast cancer of Thai women. Journal of Medical Association Thai 2007;90:282-90.

9. Uzzan B, Nicolas P, Cucherat M, Perret GY. Microvessel density as a Prognostic factor in Women with Breast Cancer: A Systematic Review of the Literature and Meta-Analysis. Cancer Res 2004; 64: 2941-2955.

10. Pansrikaew P, Cheewakriangkrai C, Taweewist M, Khunamornpong S, Siriaunkgul S. Correlation of Mast Cell Density, Angiogenesis and Clinical Outcomes in patients with Endometrioid Endometrial Cancer. Asian Pacific J Cancer Prev 2010; 11: 309-12.

11. Pyakurel D, Karki S, Agrawal CS. A study on microvascular density in breast carcinoma. Journal of Pathology of Nepal 2014; 4 :570-75.

12. Teo NB, Shoker BS, Jarvis C, Martin L, Sloane JP, Holcombe $\mathrm{C}$ et al. Angiogenesis and Invasive recurrence in Ductal Carcinoma in Situ of the Breast. Eur J Cancer 2003; 39:38-44.

13. Mousa SA. Mechanisms of Angiogenesis: Potential Therapeutic Targets, in Angiogenesis Inhibitors and Stimulators: Potential Therapeutic Implications . Landes Bio sci 2000: 1-12. 
14. Safwat MD, Habib F, Elayat A, Oweiss N, Reffat S, Algaidi S. Morphometric and Immunohistochemical study of Angiogenic Marker expressions in Invasive Ductal Carcinomas of the Human Breast. Folia Morphol 2009;68:144-55.

15. Bolat F, Kayaselcuk F, Nursal TZ, Yagmurdur MC, Bal N, Demirhan B. Microvessel Density, VEGF Expression, and Tumor associated Macrophages in Breast Tumors: Correlations with Prognostic Parameters. J Exp Clin Cancer Res 2006;25:365-72.

16. Kwon GY, Lee SD, Park ES. Mast cell and Macrophage
Counts and Microvessel Density in Invasive breast carcinoma: Comparison Analysis with Clinico Pathological Parameters. Cancer Res Treat 2005;37:103-08.

17. Amin M, Amira K, Hawary EL, Omar Farouk. Relation of CD117 immunoreactivity and microvascular density in invasive breast carcinoma. Indian Journal of Pathology and Microbiology 2012;55(4):456-60.

18. Vartanian $\mathrm{R}$, Weidner $\mathrm{N}$ : Correlation of Intratumoral Endothelial-Cell Proliferation with Microvessel Density (Tumor Angiogenesis) and Tumor-Cell Proliferation in Breast Carcinoma. Am J Pathol 1994; 144:1188-94.

*Corresponding author:

Dr. Divya rani M.N, No 1117,1st phase,1st stage,14 th cross, Nagarbhavi, Chandralayout, Bangalore-560072(India)

Phone: +91 9986020047

Email: divyaranimn@gmail.com

Financial or other Competing Interests: None. 